\title{
A Freshman Engineering Course Which Introduces Engineering Design and Engineering Fundamentals in the Context of a Unifying Theme
}

\author{
R.D. Wilk, C. Traver, C. LaPlante, J. Hedrick, W.D. Keat, F.E. Wicks \\ Division of Engineering and Computer Science \\ Union College \\ Schenectady, New York
}

\begin{abstract}
Five years ago, a new first-term freshman engineering course, Introduction to Engineering and Computer Science, was introduced to the curriculum at Union College. Since then, the course has undergone significant revision based on assessment. The current course is ambitious and seeks to accomplish several objectives. These include introducing the students to the discipline, introduction to and application of the design process and teamwork for solving problems, introduction to the concepts of ethical practices and decision-making, developing good communication skills, and introduction of some basic topics in engineering and computer science. The last of these objectives is centered about a unifying theme of intelligent transportation systems. This provides an interesting and contemporary context in which to present some fundamental engineering concepts. The course is structured with two small section lectures, one common lecture, and a 3-hour design studio session each week. The common lecture is used to bring in speakers from outside. These are typically practicing engineers from the different disciplines who talk about their area and the kind of work they do. The weekly section lectures are devoted primarily to introducing some fundamental engineering and computer science principles all tied into the concept of intelligent transportation. Three main areas are explored: Energy and Cars, Cars and Computers, and Transportation Infrastructure. In the design studio portion of the course, the students learn basic design methodology and apply it to several individual and team design exercises. They also cover ethics, project scheduling, and report preparation. The design studio also includes a 5-week long design project in which the students work in teams to design and build simple, small-scale, electromechanical devices to perform a task. The teams participate with their devices in a large design competition at the end of the term. Along the way they must satisfy project milestones and defend their design in an oral presentation before a panel of faculty judges. This paper describes the details of the current version of this course and discusses the process used to assess the effectiveness of the course.
\end{abstract}

Introduction

Over about the last ten years there has been a movement to bring more engineering content into the freshman year engineering curriculum. This has been done by incorporating new introductory engineering courses in the freshman year ${ }^{1-4}$. These courses have a variety of content but a common underlying goal is the retention of engineering students. In addition, a properly designed course will not only help retain 
engineering students but can attract students who may be interested in exploring the possibility of an engineering major.

Five years ago, a new first-term freshman engineering course, Introduction to Engineering and Computer Science, was introduced to the curriculum at Union College. Since then, the course has undergone significant revision based on assessment. There has been debate among the faculty over the course content. Should it be soft and fun, aimed at developing creativity so as not to scare away students? Or should it be more difficult and rigorous, presenting significant fundamental concepts and the development of good practices in terms of engineering analysis, problem solving, experimentation and reporting which would lay a foundation for engineering science courses in the sophomore year? The course has leaned in both of these directions over the last few years. Recently the course has sought to achieve a balance and be, on one hand, fun and interesting for the students and at the same time provide some significant coverage of some important topics in engineering and introduce the design process.

Team-based hands-on projects have been shown to be effective in making the course fun and interesting for students ${ }^{5-7}$. In recent offerings of this course, the projects include a competitive aspect. Teams within a class compete with each other on in-class design exercises and also on a term design project. In order to have significant coverage of engineering topics, the current course is ambitious and seeks to accomplish several objectives. These include introducing the students to the different engineering disciplines, introduction to and application of the design process and teamwork for solving problems, introduction to the concepts of ethical practices and decision-making, developing good communication skills, and introduction and application of some fundamental principles in engineering and computer science, including conducting analysis.

Effectively achieving the last objective has been challenging. The challenge has been in presenting different fundamental principles and finding some relevant yet simple application to be used as a context for showing a connection between them. In the 1999 version of this course, fundamental engineering and CS topics were presented each week along with some assignments to reinforce them. Student feedback on the end-of-course assessment questionnaires indicated the students felt that these topics were not well connected. Consequently we decided that for the year 2000 offering of this course there needed to be a relevant and unifying theme which could serve as a contextual basis for presenting and tying together different engineering and CS topics in this part of the course.

\section{Selection of a Course Theme}

In searching for a good course theme we had to keep in mind several criteria: (1) it should be interesting for first year engineering and computer science students, (2) it should be a contemporary topic in technology that has a significant impact on society, (3) it should be broad enough so as to be relevant to several different disciplines including EE, CS, ME, and CE, and (4) it should lend itself to the application of some fundamental 
topics in each of the preceding disciplines, and (5) it should be multidisciplinary, providing a good example of how the preceding disciplines are integrated in most practical technological systems.

Consequently, keeping these issues in mind, we chose the theme of intelligent transportation systems. This theme encompassed the topics ranging from smart cars to transportation infrastructure. This paper describes the details of the current version of this course and discusses the process used to assess the effectiveness of the course.

The course is structured with a once-a-week, 65 minute, common lecture for all five sections, and for each individual section a 3-hour design studio session and two hour-long lectures each week. The common lecture is used to bring in speakers from outside. These are typically practicing engineers from the different disciplines who talk about their area and the kind of work they do. The purpose of the design studio is to introduce the design process, and teambuilding skills. The weekly section lectures are devoted primarily to introducing some fundamental engineering and computer science principles and topics most of which are tied into the concept of intelligent vehicles.

The course is taught by a diverse group of faculty from the engineering and computer science division. The approach used when this course was initially offered five years ago was to have each faculty teach only their area of specialty, to all sections. The advantages to this were that the faculty were more comfortable with this approach and the students got to see a variety of faculty from the division. The main disadvantage was that this, by example, seemed to promote the idea that engineers need only be concerned about their narrow discipline and de-emphasized the notion that it's important for engineers to have a broad base of engineering knowledge. Since then we have adopted the approach whereby each faculty teaches a given section and covers all of the topics. This required recruitment of faculty into this course who were comfortable teaching a broad range of topics, many of which were outside of their specialty.

Student grades were based on evaluation of student performance in several areas. Weekly homework assignments from both lecture and design studio, in-class exercises/projects, design project milestones, oral and written proposal and defense of the design project, a midterm and final exam covering material from lecture and design studio. The last two items were added this year in order to ensure the students would take the course seriously.

Since the presentation of course material in both lecture and design studio was done using traditional methods as well as Powerpoint presentations, the classes were taught in an electronic classroom. For certain classes throughout the term where each student needed a computer, those classes were scheduled in a computer laboratory. A web page was created for the course and all students were responsible for obtaining announcements and assignments from this site. No textbook was used for this course. Faculty developed their own notes that were distributed to the students. 
The following describes the content of each of the three main parts of this course.

\section{Common Lecture}

All students met together once a week in an auditorium for the common lecture component of the course. Most of these lectures were devoted to speakers, selected by the faculty, from all the different engineering and computer science disciplines represented by Union's programs. The speakers were asked to prepare a talk targeted to a freshman audience that conveyed the nature of their profession and their particular job. Typical presentations included pictures of the speaker's work environment, the events of a "typical day", advice about the educational experiences they found most helpful, and some "props" related to their work. The common lecture was also used to introduce all of the faculty on the first day, for a midterm exam, and for a "car show" demonstration. The car show event occurred toward the end of the course and was related to the intelligent transportation theme of the section lectures. Demos of various vehicles, including some created by Union engineering students (Mini-Baja Car, Remote Control Robot, Formula Car) and some from local car dealers (Toyota Prius) were available for students to see. Students were asked to discover the control mechanisms and energy sources for the vehicles, two central concepts covered in the intelligent transportation theme. In the final common hour, students were informed about opportunities for co-ops and terms abroad from the directors of those programs.

\section{The Design Studio}

In the design studio component students met with their section instructor for a 3-hour session each week. A combination of demonstrations, hands-on exercises, discussions and lectures were used to convey the basic concepts of the engineering design process, team work, and engineering ethics. In the last half of the course students worked on a design project during the design studio time, and instruction was given on the basic operation of the solenoids, motors, gears and other materials used in the project. Students were also instructed on oral presentation skills and on how to write design reports.

\section{The Design Project}

A hands-on design project, with students working in teams of 3, is the central focus of the design lab. The hands-on aspect allows students to learn, through experience, the importance of fundamental design principles (esp. design for manufacture, design for robustness, and design for adjustability) while providing instructors with an objective means for evaluation. This year's project, "Hoops", was to design a small-scale electromechanical device capable of depositing up to 25 ping pong balls in a Nerf basketball hoop located $8 \mathrm{ft}$ away and 18 inches high. The machine had to fit initially in a $1 \mathrm{ft}$ cubic space, which meant that it had to both lift the balls and transport them to the basket. Students controlled the devices using two forward-off-reverse switches and one on-off switch, which were tethered to the device via overhead wires. Since this was a head-to-head competition with opposing machines starting on the same end of the table, the element of human control added to the open-endedness of the design problem. 
Students were also given tools and a box of materials and parts (see appendix) from which to construct the device. A typical student design is shown in Figure 1.

Formulation of assignments in terms of design milestones was vital for enforcing the design methodology and for maximizing student success through careful control of the timeline. The design milestones and their respective outcomes are summarized in Table 1. An important feature of the milestones is that students are required to formally test their machine 3 times before the final competition. Testing was facilitated by selecting a project with a continuous, easily measurable performance characteristic, in this case the number of ping pong balls that drop through the hoop. A grade was not assigned to the section and final competitions because of the element of luck that invariably enters in; peer pressure is usually sufficient motivation in these events. The performance test was conducted with only one machine on the table.

\section{The Competition}

A head-to-head design competition has been an integral part of the freshman course for the last three years. The results have been very positive. The large majority of student teams experienced some degree of success either while performance testing or at the competition. The final competition has been conducted in less than 3 hours consistently, usually with about 35 student teams participating.

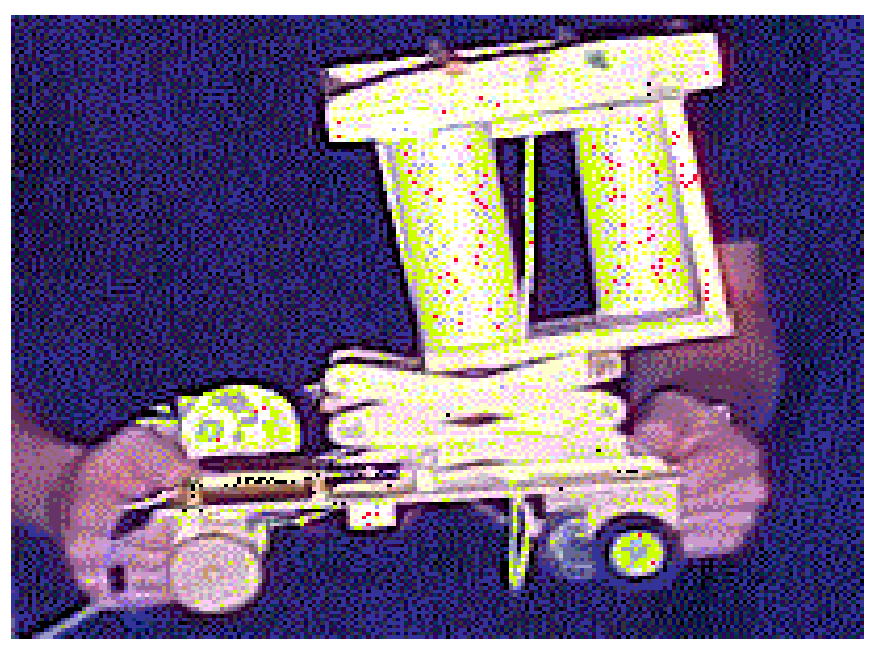

Figure 1. Typical "Hoops" Design Implementation 


\begin{tabular}{|l|l|c|}
\hline \multicolumn{1}{|c|}{ Design Milestone } & \multicolumn{1}{|c|}{ Outcomes } & $\begin{array}{c}\% \text { of } \\
\text { Grade }\end{array}$ \\
\hline Conceptual Design & $\begin{array}{l}\text {-hand sketches of 3 alternative designs } \\
\text {-discussion of strengths and weaknesses } \\
\text {-decision matrix (or Pugh Chart) }\end{array}$ & $13 \%$ \\
\hline $\begin{array}{l}\text { Detailed Design } \\
\text { and } \\
\text { Oral Design Defense }\end{array}$ & $\begin{array}{l}\text {-dimensioned drawings } \\
\text {-manufacturing schedule } \\
\text {-oral presentation before 3 faculty/staff members } \\
\text {-if they pass, they receive the tools and materials }\end{array}$ & $27 \%$ \\
\hline $\begin{array}{l}\text { Design for } \\
\text { Manufacture }\end{array}$ & $\begin{array}{l}\text {-test to determine level of functionality/nearness to } \\
\text { completion }\end{array}$ & $13 \%$ \\
\hline Performance Test & -test to determine level of performance & $27 \%$ \\
\hline Section Competition & $\begin{array}{l}\text {-small single-elimination tournament } \\
\text {-practice for final competition } \\
\text {-seedings for final competition }\end{array}$ & $0 \%$ \\
\hline Final Competition & $\begin{array}{l}\text {-all functional machines participate in this final } \\
\text { single-elimination tournament }\end{array}$ & $0 \%$ \\
\hline Design Report & -documentation of final design & $20 \%$ \\
\hline
\end{tabular}

Table 1. Design project milestones.

\section{Section Lectures}

The section lecture began with a module on introduction to computing at Union College. Topics included sending and receiving email and basics of spreadsheets. This was followed by introduction to the various engineering and computer science disciplines. The remaining section lectures in the term were devoted to presenting fundamental concepts of engineering and computer science within the context of the intelligent transportation theme. Since much of engineering and computer science revolves around problem solving, the complex problems of increasing gas mileage, decreasing pollution, and improving drivability in an automobile as well as reducing traffic congestion are presented as motivating problems. The material was divided into three main areas: Energy and Cars, Cars and Computers, and Infrastructure. Each part began with a brief historical perspective followed by introduction of some fundamental principles in each of these areas. These included basic concepts in energy, combustion, feedback and control, electric circuits, logic circuits, embedded systems, and transportation infrastructure. These were reinforced with hands-on and homework exercises matched closely to the theme. Tying the presentation of the material closely to the theme, allowed the material in the three areas to be more closely connected to each other. 


\section{Energy and Cars}

The module starts by trying to show the vital importance of energy. Civilization started with the energy conversion process of fire in which hydrocarbon fuels in the form of wood was burned and heat was recovered for comfort and cooking and later for metallurgy. The industrial revolution started in the $18^{\text {th }}$ century with the invention of steam engines that could convert the heat from a fire into mechanical work. Our electric world started at the end of the $19^{\text {th }}$ century with the conversion of mechanical power from falling water and from steam engines into electric power and reconversion to light and mechanical power and later to power electronics.

Modern transportation started when horses were replaced first with the steam engines for railroads then with the 1876 invention of the four-cycle internal combustion engine by Nicolas Otto that led to the personal automobile. The automobile required an infrastructure of roads and bridges by civil engineers and then electric systems for starting and auxiliaries followed by computer control of the engine over the last two decades.

The resulting module focused on energy and cars. We started with the definition of energy, including the definitions of potential and kinetic energy, and described the energy conversion process. This led to the combustion process of hydrocarbon fuels.

Combustion is presented as a chemical process in which a hydrocarbon fuel in oxidized with the resulting products of carbon dioxide and water. The energy released in the form of heat is the difference of the binding energies between the reactants and products. Using chemical heats of formation, the heating value of a fuel was calculated from the balanced chemical equation for combustion.

Next the four cycle engine was demonstrated in the form of a single cylinder air cooled Briggs and Stratton. An engine was dismantled and the stroke, bore and clearance volume were measured from which the compression ratio was calculated. The efficiency of the ideal cycle was computed from the compression ratio. The power was calculated as a function of displacement, rpm, heat value of the fuel and efficiency.

The vital operating requirements of the engine were shown in terms of intake, exhaust and spark and an optional speed controlling governor. The action of the cam shaft, cams and valves for intake and exhaust was demonstrated along with the production of the spark by a spark plug which is supplied by a magneto and coil and activated by a switching action. The principle of a speed control governor was described in terms of the need for a set point, a measured value and an error signal proportional to the difference to make corrective adjustments. It was shown how the speed setting lever stretches a spring to establish the set point, how the aerodynamic force from the blades on a vane produces a force which is a function of the measured speed and how the linkage is the summing junction that responds to the difference of these two forces to open or close the throttle as necessary to retain the desired set point speed. 
Student response from this part of the energy and cars module was varied but mostly favorable. Most students showed appropriate interest and enthusiasm. A few indicated that more time was needed on concepts of energy and the technology of cars.

\section{Cars and Computers}

Fuels, combustion, and the air/fuel ratio are discussed in the cars and energy section. In the cars and computing section students study some of the methods currently available for controlling the air/fuel mixture in an automobile in order to provide maximum efficiency and performance. The fundamentals of both mechanical and computer based feedback and control systems are discussed. It is pointed out that computer control is used in automotive control systems because mechanical feedback systems cannot respond quickly enough and cannot be flexible enough to have different behaviors for several different situations. With this in mind, students take a brief look at the development of the digital computer and its use as a control element. In the process, the fundamentals of logic, Boolean algebra and truth tables are studied.

Electronic circuit analysis using Ohm's law and the power equation are used to understand how electronic circuits can be used to implement digital logic and finally, how logic circuits can be combined to create a computer Central Processing Unit (CPU) to provide the "brain" of a computer system. Computer programming is studied as well as the connection between the software and hardware. In order to use a CPU to control the air/fuel mixture in an automobile the exhaust oxygen content must be measured and the $\mathrm{CPU}$ need to be able to control the amount of fuel injected into the engine. Thus, sensors, actuators, analog to digital converters, and analog to digital converters are studied. To complete the discussion of computer control of the air/fuel mixture in an automobile, a block diagram of the feedback system is drawn and an algorithm for the software to run the system is developed.

The hands-on exercise for the Cars and Computers section demonstrated the concept of an embedded controller. Several BASIC Stamp microcontroller boards were configured with a switch input and 6 LED outputs to model a traffic light. Students analyzed and modified simple BASIC programs and then downloaded them to control the traffic light. The ability to re-program the microcontrollers to get a different behavior, and the ability for the microcontroller to respond to the switch input clearly demonstrated the flexibility and adaptability of embedded controllers.

\section{Transportation Infrastructure}

"Survivor" was the name of a hit television program during the summer of 2000. It portrays a group of people stranded on an island. Their individual survival depended only upon their own resourcefulness. They had to survive without the infrastructure they had been accustomed to before their stranded ordeal. They had to live without public roads and bridges, public transportation in the form of buses and airplanes, sanitary water supplies and sewers, solid waste removal, public parks and buildings and energy supplies in the form of electricity and gas. 
The Survivor conditions are used to help define for the freshmen Introduction to Engineering students what life is like without an infrastructure. It also represents what life was like a century ago when overland transportation was mostly by horse drawn carriages. It's what could happen today if our infrastructure is not properly maintained and upgraded in response to aging equipment and rising population.

The modern infrastructure resulted from the development of the internal combustion engine for vehicles and the introduction of electric power, modern plumbing and solid waste removal. It is mostly either publicly owned such as roads or privately owned but publicly regulated monopolies such as electricity.

After defining what the infrastructure means, this section defines the agencies responsible for each. For example, the construction and maintenance roads and highways are the responsibility of a combination of village, town, city, county, state and federal agencies. The electric power system and gas pipelines that are typically privately owned monopolies are regulated by state and federal agencies. Water supplies are mostly publicly owned but overseen by various departments of public health. Solid waste disposal is regulated by a combination of local, state and federal environmental monitoring and control agencies.

This unit then focuses on roads and highways. Asphalt and concrete are compared in terms of cost, characteristics and the conditions under which either one is preferable. Concrete is required under high temperature pavement conditions whereas asphalt is generally lower cost. Topographical maps were presented along with drainage basins, requirements and techniques. Intelligent Transportation Systems such as computer based EZ Pass systems were described. A dashboard mounted EZ Pass transponder was shown and its operation described as similar to the transponder on airplanes that send an encoded response to the radar signal from the control tower.

As a capstone assignment each student was asked to access the Web page of their hometown and learn about one of the infrastructures and write an essay about it. The resulting papers covered the expected spectrum of water, roads, sewers and solid waste along with less expected infrastructures such as a public harbor and tour boat. This project gave both the students and the faculty an opportunity to expand their knowledge and appreciation of public infrastructures along with problems and opportunities.

\section{Course Assessment}

The Introduction to Engineering and Computer Science is an integral and important course for all of the engineering and computer science programs at Union College. It is therefore very important to assess the success of the course in meeting its objectives and develop ideas for continual improvement. Assessment measures used in the Fall 2000 offering include:

- End of course faculty evaluations to assess the effectiveness of individual instructors 
- Student surveys that ask students their opinions of how well objectives are met.

- Assessment of student experiences in the class using EnableOA software ${ }^{1}$.

- Faculty team assessment of the course

- Presentation to the Engineering and Computer Science Division and solicitation of feedback

The significant change to the assessment process over previous years is the introduction of the EnableOA software and the presentation of the course to the Engineering and Computer Science Division. The EnableOA software is used for assessment based primarily on student experiences, entered by the students themselves, and supplemented with actual student work. The software allows students to develop a software portfolio of their work, and does an automatic accounting of the number of experiences entered for particular course and program outcomes. Faculty also enter course plans into the software to define the experiences (assignments, material, field trips, projects, etc) in the course that address the program outcomes. The software produces graphs, such as the one displayed in figure 2, to show the number of experiences entered for each program outcome, as well as other reports for assessment purposes.

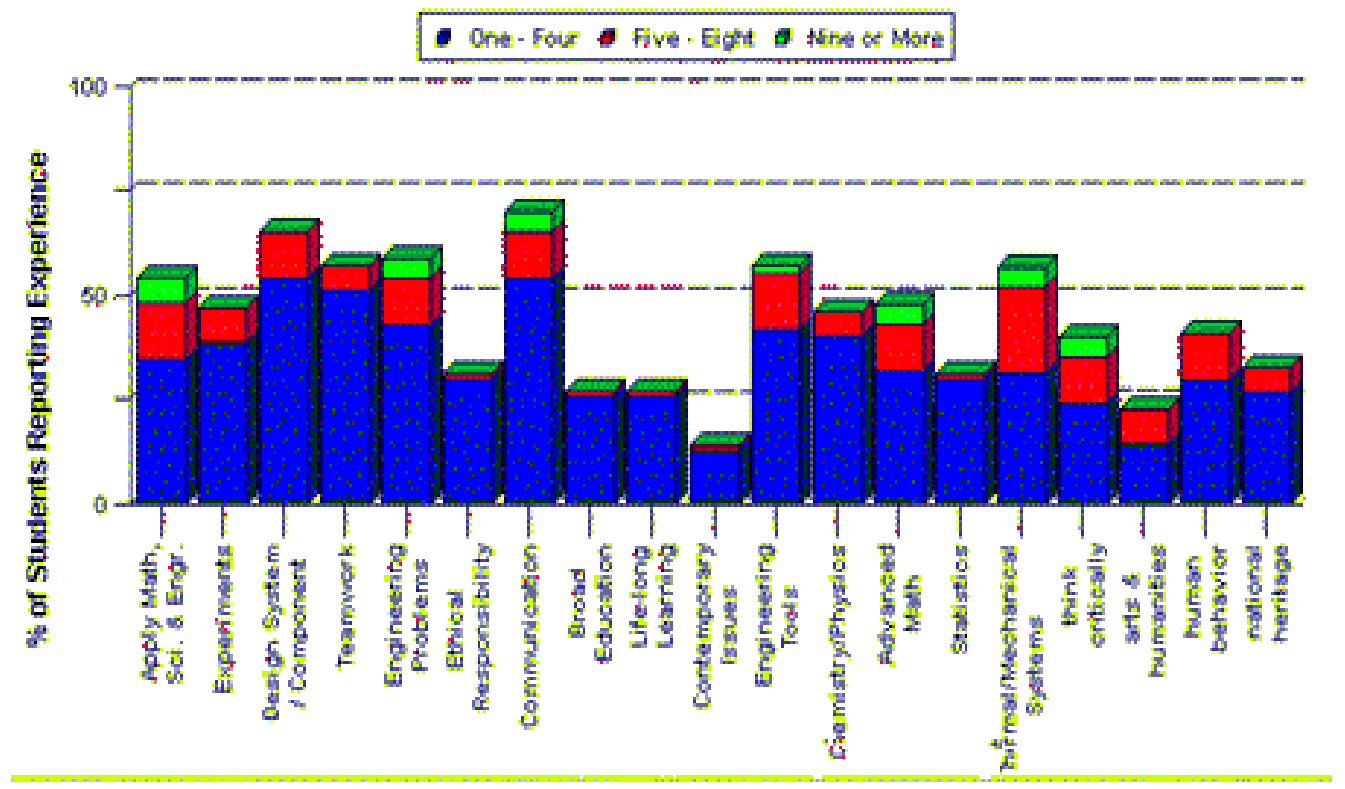

Figure 2. Output Graph from EnableOA Software

The presentation of the course to the Engineering and Computer Science Division is an important new assessment process that introduces an external peer review of the course. A division meeting is allocated to a presentation of the course contents, and feedback from the faculty is included as one of the consideration for course improvements.

\footnotetext{
${ }^{1}$ Enable Technologies Inc. "Innovators in Outcomes Assessment". http://www.enableoa.com.
} 
The results of the assessment instruments are collected by the Dean of Engineering who manages the course. He discusses them with the faculty and suggests changes for the following year. Results from the assessment process will be available when the final version of this paper is prepared.

\section{Summary and Conclusions}

This paper presents the results of a recent revision of Union College's Introduction to Engineering and Computer Science course. The changes include the introduction of a design project and competition, the presentation of engineering and computer science concepts under a unifying theme, and the introduction of weekly talks from outside speakers. The course instruction also changed from a series of modules taught by different faculty to a structure in which all of the faculty taught all of the topics in the course. Faculty involved in the course found that teamwork was not just a topic for the design studio, it was an essential aspect of teaching the course. Faculty were all involved in teaching and learning from each other. This took the form of providing background material and developing visual aids and homework solutions for other faculty, passing demonstration materials around, passing along advice about design studio experiences, and even sitting in on each others lectures to be better prepared to present the material. If this approach is used with a group of cooperative faculty, the benefits of the exposure to different teaching styles and understanding of other disciplines can be extremely positive and rewarding and will ultimately benefit the students.

Bibliography

1. Ercolano, V., "Designing Freshmen,” ASEE Prism, April (1996).

2. Ambrose, S. A. and Amon, C.H., "Systematic Design of a First-Year Mechanical Engineering Course at Carnegie Mellon University," Journal of Engineering Education, V 86, n 2, 1997, p.173-181.

3. Barr, R.E., Schmidt, P.S., Krueger, T.J. and Twu, C.Y., "An Introduction to Engineering Through an Integrated Reverse Engineering and Design Graphics Project," Journal of Engineering Education, V 89, n 4, 2000, p. 413-418.

4. Wilson, S.S., "Introducing Freshmen to Engineering at Western Kentucky University", Proceedings of the ASEE Annual Conference, June 2000, Session 2326.

5. Marchese, A.J., Hesketh, R.P., Jahan, K, Chandrupatla, T.R., Dusseau, R.A., Slater, C.S., and Schmalzel, J.L., "Design in the Rowan University Freshman Engineering Clinic," Proceedings of the1997 ASEE Annual Conference, June 1997, Session 3225.

6. Macedo, J.A., Lord, S.M., and Olson, R.T., "A NIFTY Laboratory for First Year Engineering Students," Proceedings of the2000 Annual ASEE Conference, June 2000, Session 2553.

7. Dally, J.W. and Zhang, G.M., "A Freshmen Engineering Design Course," Journal of Engineering Education, V 82, n 2, 1993, p. 83-90.

Proceedings of the 2001 American Society for Engineering Education Annual Conference \& Exposition Copyright (C) 2001, American Society for Engineering Education 
RICHARD D. WILK

Richard D. Wilk is an Associate Professor at Union College. He received his B.S, M.S. and Ph.D. in Mechanical Engineering from Drexel University. He conducts research in the fields of combustion and alternative energy systems and teaches courses in freshman design, thermodynamics, heat transfer, solar energy and design of thermal-fluid systems.

\section{CHERRICE TRAVER}

Cherrice Traver is a Professor of Electrical Engineering and Computer Science at Union College and is the Director of the Computer Systems Engineering program. She received her B.S. in Physics from the State University of New York at Albany and her Ph.D. in Electrical Engineering from the University of Virginia. She conducts research in the area of VLSI synthesis and digital logic and teaches courses in freshman design, digital logic, digital design, computer architecture and VLSI.

\section{CHRISTINE LAPLANTE}

Christine LaPlante is an Assistant Professor of Civil Engineering at Union College. She received her B.S., M.S. and Ph.D. in Civil Engineering from Rensselaer Polytechnic Institute and is a licensed professional engineer. She conducts research in the fields of construction management, geo-environmental engineering and landfill design and teaches courses in freshman design, construction management and senior design.

\section{JAMES HEDRICK}

James Hedrick received a B.S. and M.S. in Electrical Engineering from Union College. He has taught both electrical engineering and computer science for the past five years in the EE/CS department at Union College. In addition to teaching, he is the Associate Director of the Union College Academic Opportunity Program.

\section{WILLIAM D. KEAT}

William D. Keat is an Assistant Professor of Mechanical Engineering at Union College. He received his B.S. and M.S. in Mechanical Engineering from Worcester Polytechnic Institute and a Ph.D. in Mechanical Engineering from the Massachusetts Institute of Technology. His conducts research on the development of computational models for 3D fracture analysis with applications ranging from nondestructive detection of subsurface flaws to modeling of fatigue crack growth in structural components and he teaches courses in freshman design, mechanics, dynamics and kinematics, design of mechanical systems, and fracture analysis.

\section{FRANK E. WICKS}

Frank E. Wicks is an Associate Professor of Mechanical Engineering at Union College and a licensed professional engineer. He received his BMarineE from New York Maritime College, a M.S. in Electrical Engineering from Union College and a Ph.D. in Nuclear Engineering from Rensselaer Polytechnic Institute. He worked as a General Electric Company Engineer in aircraft engines, turbines, nuclear products and power systems. He served as Supervisor of Nuclear Operations at Rensselaer. Within ASEE he has served in all the officer positions in the Energy Conversion and Conservation Division. He conducts research in the field of energy conversion and teaches courses in freshman design, thermoduynamics I, II, heat transfer, HVAC and nuclear engineering. 


\section{Appendix}

Detailed List of Parts:

\begin{tabular}{|c|c|}
\hline 1 & motor with adjustable gear box \\
\hline 1 & gearhead motor \\
\hline 1 & relay (for use with gearhead motor) \\
\hline 1 & diode (for use with gearhead motor) \\
\hline 1 & pull solenoid \\
\hline 1 & set of 6 gears \\
\hline 1 & wooden dowel, 3/8" x 36" \\
\hline 2 & balsa sheets, $1 / 16 "$ × $3 "$ × $36 "$ \\
\hline 2 & balsa beams, $3 / 8 "$ × $3 / 8 "$ x $36 "$ \\
\hline 1 & plywood sheet, $1 / 4 "$ × $12 " \times 12 "$ \\
\hline 10 & super craft sticks \\
\hline 1 & steel rod, $1 / 8 " \mathrm{D}$ x $20 "$ \\
\hline 1 & piece of string, 10'long \\
\hline 2 & metal hinges, 1 " long \\
\hline 1 & shock cord (with hooks on both ends), 1/4"D x 10" long \\
\hline 1 & rubber band strip, 3' long \\
\hline 2 & wheels with hubs, $2 " \mathrm{D}$ (for $1 / 8$ " shaft diameter) \\
\hline 1 & mailing tube \\
\hline 1 & 2 liter (plastic) soft drink bottle (provided by contestant) \\
\hline
\end{tabular}

Regarding fasteners:

Teams are responsible for purchasing fasteners. Typical options for fasteners include: wood glue, epoxy, screws, tacks, duct tape, hose clamps, and shaft couplers with set screws. 